\title{
Highlighting product issues during design phase using functional analysis
}

\author{
Felicia Veronica Banciu ${ }^{1, *}$, and Eugen Pămîntaş ${ }^{1}$ \\ ${ }^{1}$ Politehnica University of Timişoara, Mechanical Faculty, IMF Department, 300222 Mihai Viteazu \\ Bv. Timişoara, Romania
}

\begin{abstract}
The major costs of a product take place in product design stage and essential elements like i. e. ease of assembly, components accessibility in an assembly, disassembly, number of parts have to be taken into account during product design stage. The paper aim is to gain understanding and improvement of overall engineering skills and thinking of engineering students with regard to the design/redesign process for a product from a functional perspective with the aim of extracting information for design and manufacturing associated design. The model is based on functional modelling and analysis of product using Function Block Diagram. Functional analysis helps to identify components' functions and interactions between products parts, they describing also, the functioning. Analysing these functions and interactions between product's parts offer an overview on their number, their interactions useful for example in assembly. Starting from a functional modelling and analysis, creativity techniques could be used in order to generate alternative solutions with regard to products design, manufacturing and assembly.
\end{abstract}

\section{Introduction}

Designers must be able to see the effects that their decisions produce on the manufacture, assembly, maintenance and recycling processes. They must be familiar with the general principles of design, manufacturing and specialized knowledge to solve complex design tasks like assembly-disassembly-reassembly. Assembly and a majority of the problems attached are determined by design.

The issue of expressing functional decomposition, the taxonomy of this area was and still is a current theme. In literature, there are many strategies on functional decomposition and functional models [1-3]. Functional decomposition is an extensive subject in engineering, its development and study reasons are mainly finding a common language for designers and the need for sharing engineering knowledge, understood by everyone involved in design process. This is important from the perspective of using a common language between designers and reuse knowledge attached functional models [1].

A better sedimentation of knowledge, completing the design tasks with the overall picture of the importance that functional products decomposition occupies in analysing similar products is considered in this paper. In order to emphasise the functional blocs that

${ }^{*}$ Corresponding author: felicia.banciu@upt.ro 
accomplish the same task but using different structural components offering in the same time a concise and visual link between product parts and their links to each other will be used a functional approach based on FBD.

Examining existing solutions and new solutions involves both logic and creation and it is about a complex phenomenon that must train in order to develop the creative thinking, the following: divergent thinking: association, extrapolating, generalizing combining imagination, the ability to view static and dynamic [4].

Thus, the paper proposes an approach to the design/redesign process for a product from a functional perspective aiming to extract information related to functional structure, number of product part's associated to functions (needed to achieve them) from conceptual design phase.

\section{The functional approach}

Fundamental to existing approaches is the notion of function and functions decomposition, possibly on hierarchical levels and then highlighting behavioural links between these functions. Functional structures are attached to constructive structures and follows the logic of what we want and how we get, logic meet practical both in systematic as well in the axiomatic approaches on product design $[3,5]$. A highlight of functions and information extraction related to assembly and what implies induce an alternative thinking, extended possibly to other solutions or oriented to solve the existing ones and different methods of creativity could be used. A representation of functions by functional blocks, the functions being arranged hierarchically - FBD Model- is presented in [2]. Structurally, the functions are divided into basic functions and secondary functions that help achieve basic functions. The function is a pair verb-noun the verb expressing an action and the noun is measurable. Between the various elements of functions exists links like and / or temporal link, the causal links that cause so-called side effects- effects of the implementation of certain functions. A hierarchy of functions leads to a hierarchy of parts and components. FBD elements, functions, does not specify uniquely a physical form but the sequencing logic functions can stimulate creativity. The product is basically a sum of functions that are attached to components and subassemblies.

Thus, the starting point for a design consists of the main function, the role that products have, the reason of their existence. This primary function is then decomposed into levels of sub-functions leading to sub-assemblies and components of the product.

\section{Applied approach}

As a starting point for achieving the purpose of the work was chosen FBD approach - in American literature presented by [2] and in the French by the APTE society [6].

For example, consider two types of devices, mandrels used for fixing and centring parts on parts inner cylindrical surfaces, one with wedges and plungers in figure 1 and one with balls in figure 2. To analyse the reference solutions it is used FBD (Functional Block Diagram). This tool makes easier to emphasize the aggregate of elementary functions and their assignment to basic and design functions. More information about developing a FBD can be found in [6-7].

To realize a FBD we have to build a graphic and dispose all the composing elements of the product or subassemblies in contact relation, to identify external and internal contacts and also the open streams and the closed streams that are relations between different product's elements because of its designing. They can be external opened streams, which integrate the relations between some of the products components with one or more external 
environments, respectively internal closed streams that take into account just the product's components. Closed streams are sources for potential optimization as they could be achieved through different solutions. Using an internal functional analysis decomposition, it can be developed a functional structure that in its turn conducts to the solution dependent functions. Each technical solution has associated good functioning criterions or conditions that allow their performance level definition.

The principle functional scheme of mandrel with wedges and plungers used for centring and fixing work pieces on their inner cylindrical surfaces [8] is presented in figure 1. Its components are: 2 plungers, 3 wedges, 4 rolls, 5 stem with double slope area, 6 elastic elements, 7 springs, 8 mandrel body, 9 locating pin, 10 cover and 1 work piece. The stems is pulled to left, the balls "mount" on stem's sloped area and next transmit movement to multiple wedges 3 that transmit movement and force to plungers 2 that will move synchronous on radial direction. In this way, first it is consumed the clearance up to work piece and next is done the clamping.

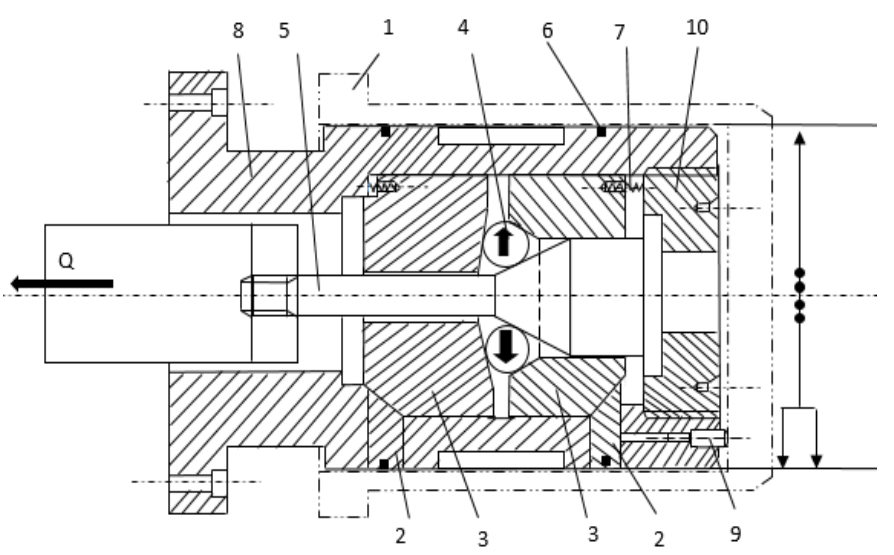

Fig. 1. Scheme of mandrel with wedges and plungers [8]

The functional principle scheme of mandrel with balls used for centring and fixing work pieces on their inner cylindrical surfaces is presented in figure 2 [9]. Its components are 1 the mandrel body with sloped area, 2 stem with threaded end, 3 balls with different diameters, 4 balls cover, 5 nut, 6 washer.

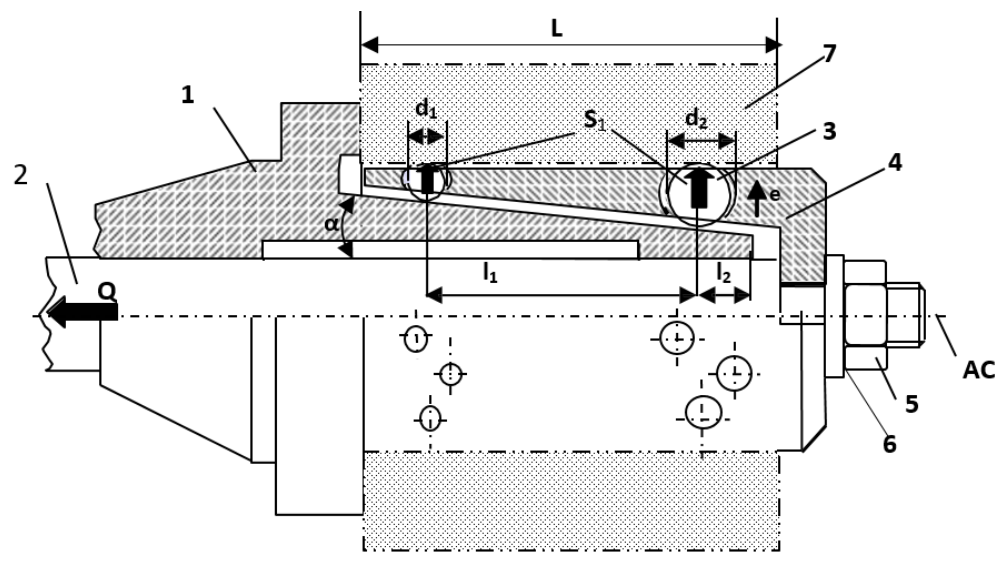

Fig. 2. Scheme of mandrel with balls [9] 
The balls cover moves together with stem. It is mounted on the stem using a washer 6 and a nut 5 . The stems is pulled to left by the actuating mechanism, the balls cover 4 (jointed with stem through nut and washer) is moved to left and the balls 3 , that are in balls cover, "mount" on CD' sloped area and next consume the clearance up to work piece 7 and (their movement being stopped by the work piece) is realised its clamping.

Table 1 presents the main functions and their corresponding technical functions and they are the same for analysed examples.

Table 1. The main functions and their corresponding technical functions

\begin{tabular}{|l|l|}
\hline The main functions (noted FP) & $\begin{array}{l}\text { Corresponding technical functions for main } \\
\text { functions }\end{array}$ \\
\hline $\begin{array}{l}\text { FP1 centring the work piece on inner } \\
\text { cylindrical surface and prevent the } \\
\text { movement of the piece }\end{array}$ & $\begin{array}{l}\text { FT1 - use up clearance between work piece and } \\
\text { elements that move radial, their contact with the } \\
\text { work piece and work piece clamping }\end{array}$ \\
\hline FP 2 Hold the piece against locator & FT2 - Block work piece axial movement \\
\hline
\end{tabular}

In figures 3 and 4 are presented the FBD diagram and the functions identified following a FBD are next depicted and table 2.

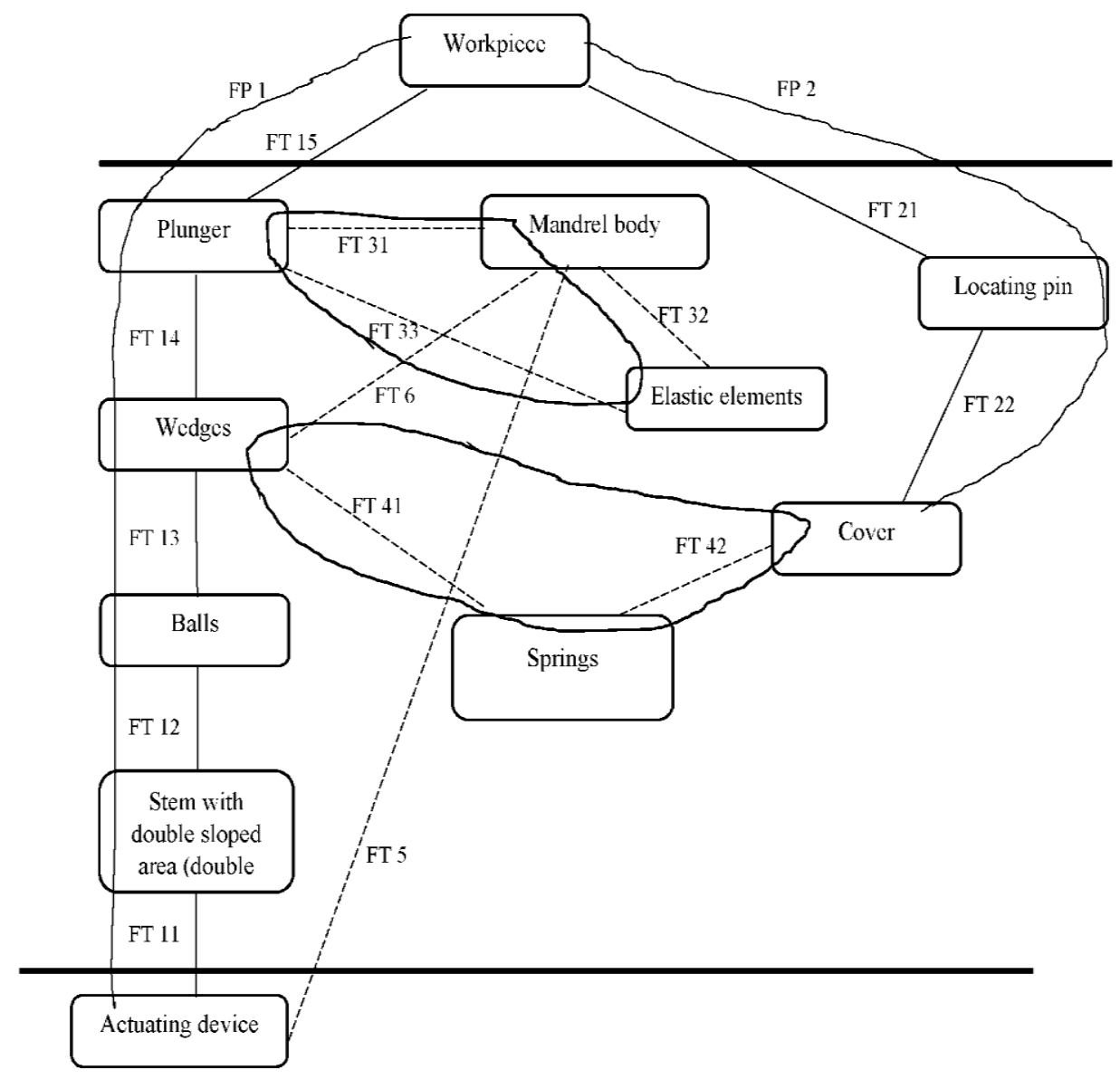

Fig. 3. FBD for mandrel with wedges and plungers - centering and fixing on inner cylindrical surfaces 


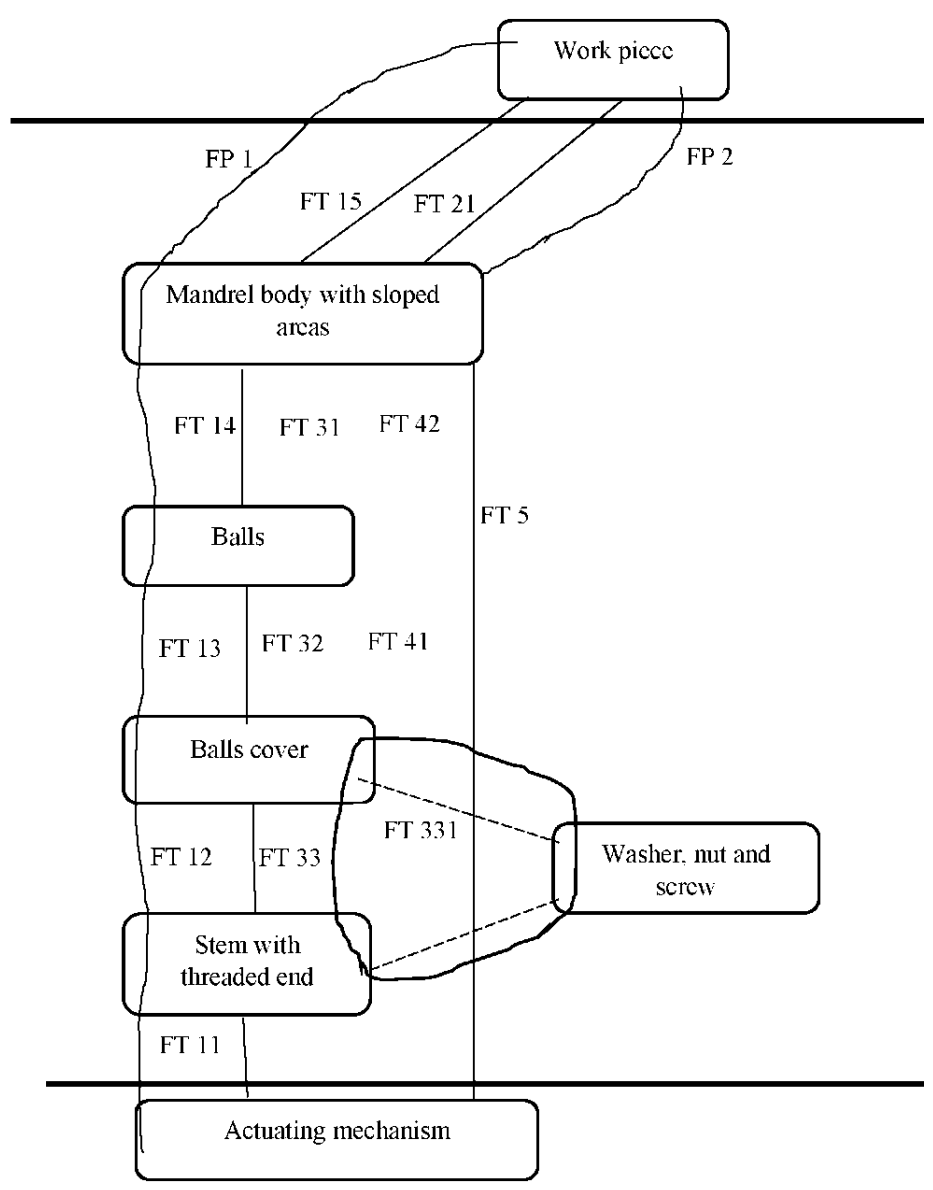

Fig. 4. FBD for mandrel with balls - centring and fixing on inner cylindrical surfaces

The way that these functions are accomplished differ, namely the way in which technical functions are realised is different. The functional analyse FBD for these mandrel emphasise the following:

An opened stream is that between the actuating device and the work piece through the mandrel's elements that transmit movement and force in order to achieve the main functions. Resuming, the main function FP1 uses functions FT11 - FT15. In both cases, the route is the same, only the components involved are different. In figure 1 and 2 the main functional chains needed to achieve the main functions FP1 and FP2 are drawn with free lines and link work piece with actuating device. The ways that these functions are accomplished differ, namely the way in which technical functions are realised is different. The functional analyse FBD for these mandrel emphasise the following:

For first example the second opened stream is between the cover, locating pin and work piece and the main function FP2 is achieved through FT21 and FT22.This second opened stream, in figure 4 is obtained through work piece and a locating surface - the mandrel body. In this case, this solution eliminates the need for a third piece, and obviously the necessity to assemble them for example. In figure 3 the closed streams are that given by contacts between elements in order to hold them in place and to assure the reversal movement for wedges (see figure 3): realise technical function FT3 - hold the plungers in place against the mandrel body - between the plungers-mandrel body and the elastic 
elements and the second -realise the technical function FT4 to assure the reverse movement for wedges between the wedge-spring- cover. For the mandrel with balls, we could observe that technical functions, realising FT3 and FT4 is done using the same functional chain as that for FP1 that implies no other components. In these cases, it remains to compare the rest of eventual assembly process that could say if one or another.

In the same time, each function could be analysed also from a useful/harmful point of view. In this way a complete function structure can be obtained, a more clear view and maybe opportunities to improve functions that lead to other solutions. In this regard friction forces has both positive and negative aspects (they are reduced by using balls, also they are needed to assure the contact and force transmitting between parts), the materials for pieces -e.g. it is necessary that balls do not leave marks on sloped surfaces.

Taking into account that this mandrels are with moving elements, their accuracy relatively to another types of mandrels proper to deliver the main functions can be discussed.

Table 2. The technical functions (FT) and their decomposition (left column - right column)

\begin{tabular}{|c|c|c|}
\hline & Mandrel 1 & Mandrel 2 \\
\hline $\begin{array}{l}\text { FT1 needed for } \\
\text { achieving the primary } \\
\text { useful function FP1 is } \\
\text { achieved following the } \\
\text { next functional chain } \\
\text { between actuating } \\
\text { system and piece }\end{array}$ & $\begin{array}{l}\text { FT11- transmit movement from } \\
\text { actuating mechanism to the stem } \\
\text { with double sloping area (double } \\
\text { wedge zone) } \\
\text { FT12-transmit the movement to rolls } \\
\text { FT13- transmit the movement to } \\
\text { wedges } \\
\text { FT14 - transmit the movement } \\
\text { synchronous to plungers } \\
\text { FT15 - due to their movement use } \\
\text { up clearance between work piece } \\
\text { and mandrel body and next } \\
\text { transmit clamping force to the } \\
\text { work piece }\end{array}$ & $\begin{array}{l}\text { FT11 transmit movement from } \\
\text { actuating mechanism to the stem } \\
\text { with threaded end } \\
\text { FT12 transmit movement from stem } \\
\text { to balls cover } \\
\text { FT13 transmit movement to balls } \\
\text { FT14 balls movement on mandrel's } \\
\text { body sloped areas } \\
\text { FT } 15 \text { due to their movement use up } \\
\text { clearance between work piece and } \\
\text { mandrel body and next transmit } \\
\text { clamping force to the work piece }\end{array}$ \\
\hline $\begin{array}{l}\text { FP2 Hold the piece } \\
\text { against locator is done } \\
\text { through technical } \\
\text { function FT2 that } \\
\text { implies: }\end{array}$ & $\begin{array}{l}\text { FT21 - a contact between cover- } \\
\text { locating pin } \\
\text { FT22 - contact between piece and } \\
\text { locating pin }\end{array}$ & $\begin{array}{l}\text { FT21 contact between work piece } \\
\text { and mandrel body }\end{array}$ \\
\hline $\begin{array}{l}\text { FT3-hold the plungers } \\
\text { in place against the } \\
\text { mandrel body - } \\
\text { auxiliary function } \\
\text { FT3 Hold the balls in } \\
\text { place against mandrel } \\
\text { body }\end{array}$ & $\begin{array}{l}\text { FT31 contact between plungers } \\
\text { and mandrel body } \\
\text { FT32 contact between mandrel } \\
\text { body and elastic elements } \\
\text { FT33 contact between plungers } \\
\text { and elastic elements }\end{array}$ & $\begin{array}{l}\text { FT31 contact between balls and } \\
\text { sloped part of mandrel body } \\
\text { FT32 contact between balls and balls } \\
\text { cover } \\
\text { FT33 contact between balls cover } \\
\text { and stem } \\
\text { FT331 screw on stem's threaded end } \\
\text { in contact with balls cover }\end{array}$ \\
\hline $\begin{array}{l}\text { FT4 - assure the reverse } \\
\text { movement for wedges - } \\
\text { auxiliary function } \\
\text { FT4 - assure the reverse } \\
\text { movement for balls - } \\
\text { auxiliary function }\end{array}$ & $\begin{array}{l}\text { FT41-contact between wedge and } \\
\text { spring } \\
\text { FT42-Contact between spring and } \\
\text { cover }\end{array}$ & $\begin{array}{l}\text { FT41 contact between balls and balls } \\
\text { cover } \\
\text { FT } 42 \text { contact between balls and } \\
\text { mandrel body }\end{array}$ \\
\hline
\end{tabular}




\begin{tabular}{|l|l|l|}
\hline FT5 contact between & $X$ & $\mathrm{X}$ \\
actuating device and & & \\
mandrel body - & & \\
auxiliary function & & - \\
\hline FT6 - contact between & $\mathrm{x}$ & \\
wedge and mandrel & & \\
body - auxiliary & & \\
function & & \\
\hline
\end{tabular}

\section{Conclusions}

By decomposing a product functionally then identifying its components according to functional decomposition it is achieved a better understanding of implications, number of parts, their contacts and links in order to accomplish the main function. Each identified function, its link between two parts means a process of joining, and adding parts together assembly. Possibilities of achieving a closed stream generates a series of alternatives and the selection of a variant or the other can be done by analysing these solutions in terms of assembly.

For the work described in this paper, the approach proposed conduct to the following achievements: 1) inventory of functions and ways to achieve them (to carry them out); 2) identify the open and closed streams; 3 ) analyse the base solution and alternatives (the parts number as a way of facilitating the extraction of alternatives and choosing the best from the assembly process point of view). Information attached to functional models are numerous and as the design progresses they are multiplied so even in the case of simple products with a reduced number of components, inventory all aspects of the design and what involves it is an overwhelming work, that is why it must be carried out by a team, not just by one person.

This paper presented an approach from a functional perspective of design process that helps to build an overall picture of product itself, its internal links between its components, which leads to improvement of overall engineering skills, and thinking of a design team members.

This research acknowledges to Walter Tools SRL, Timişoara Romania and Universitary Association of Manufacturing Engineering in supporting literature research, information gathering and support financial funding for this paper. The valuable comments from anonymous reviewers are greatly acknowledged to help improve the paper's quality.

\section{References}

1. C.F. Kirschman, G.M. Fadel, C.C. Jara-Almonte, J. Mech. Des. 120(3), 475 (1998)

2. Robert H. Sturges, Artificial Intelligence in Design '92, (Springer Netherlands, 1992)

3. G. Pahl, et al., Engineering Design - A Systematic Approach, (Springer, 2007)

4. V. Belous, Technical Innovation in Machine Building, (Ed. Junimea Iasi, 1986)

5. Dingmar van Eck, Functional Decomposition: On Rationality and Incommensurability in Engineering (Available at: https://repository.tudelft.nl/islandora/object/uuid:b2423a0a-6d5b4149-9e1e-95f0396f6f74? collection=research)

6. *** http://www.wikiwand.com/fr/M\%C3\%A9thode_APTE, Accesed 05.01.2017

7. C. Petitdemange, Design Control through Value Analysis, (Editions Lavoisier Tec \& Doc, Paris, 1992)

8. S. V. Roşculeț, N. Gojinețchi, C. Andronic et al., Proiectarea Dispozitivelor, (E.D.P., Bucureşti, 1982)

9. I. Grozav, Dispozitive în constructi de maşini, (Politehnica Publishing House Timişoara, (2008) 